ORIGINAL ARTICLE

\title{
Population based study on the outcome of small for gestational age newborns
}

\author{
D B Bartels, L Kreienbrock, O Dammann, P Wenzlaff, C F Poets
}

Arch Dis Child Fetal Neonatal Ed 2005;90:F53-F59. doi: 10.1136/adc.2004.053892

See end of article for authors' affiliations ......................

Correspondence to: Professor Poets, Department of Neonatology, University Hospital Tübingen, Calwerstr 7, D-72076 Tübingen, Germany; christian-f.poets@ med.uni-tuebingen.de

Accepted 8 September 2004

\begin{abstract}
Objective: To explore whether and how population based data from a regional quality control programme can be used to investigate the hypothesis that small for gestational age (SGA) very low birthweight infants (VLBW, <1500 g) are at increased risk of death, severe intraventricular haemorrhage (IVH), and periventricular leucomalacia (PVL), but at decreased risk of respiratory distress syndrome (RDS).

Methods: Analyses of population based perinatal/neonatal data (1991-96) from a quality control programme in Lower Saxony, Germany. After assessment of data validity and representativeness, exclusion criteria were defined: birth weight $>90$ th centile, severe malformations, siblings of multiple births, and gestational age (GA) $<25$ or $>29$ weeks. Outcomes of interest were death, severe IVH, PVL, and RDS. Multivariable analyses were performed by Cox proportional hazard and logistic regression models.

Results: Within the data validation procedure, an increase in proportions of both VLBW (from $0.95 \%$ in 1991 to $1.11 \%$ in $1996 ;+17 \%$ ) and SGA (from $22.7 \%$ to $27.4 \% ;+21 \%$ ) infants became apparent $(p<0.05)$. The study population consisted of 1623 infants (173 SGA). Mortality was $12.1 \%(n=196)$, with an adjusted hazard ratio for SGA infants of $2.54,95 \%$ confidence interval $(\mathrm{Cl}) 1.70$ to 3.79 . Both groups were at similar risk of severe IVH (adjusted odds ratio $0.93,95 \% \mathrm{Cl} 0.5$ to 1.65 ) and PVL (1.54, $95 \% \mathrm{Cl} 0.78$ to 2.87$)$, but SGA infants had less $\operatorname{RDS}(0.57,95 \% \mathrm{Cl} 0.35$ to 0.93$)$. Male sex, multiple birth, hypothermia $\left(<35.5^{\circ} \mathrm{C}\right)$, and sepsis were associated with IVH and RDS. Infants admitted to hospitals with $<36$ VLBW admissions/year had increased mortality (adjusted hazard ratio $1.56,95 \% \mathrm{Cl} 1.12$ to 2.18 ). Conclusions: SGA VLBW infants are at increased risk of death, but not of IVH and PVL, and at decreased risk of RDS. That mortality is higher in smaller hospitals needs further investigation.
\end{abstract}

$\mathrm{F}$ etal growth restriction is a complication of pregnancy that often results in a small for gestational age (SGA) newborn, defined as a birth weight below the 10th centile. ${ }^{1}$ In populations that include both term and preterm newborns, SGA infants are at increased risk of postnatal complications. $^{23}$

In populations of preterm newborns, however, the situation is less straightforward. Populations defined by very low birthweight (VLBW, <1500 g) and/or data obtained for other purposes are often used for epidemiological analyses, ${ }^{4-7}$ but not properly validated and prepared for the study under question, potentially causing bias.

We conducted a population based study with validated data on multiple neonatal outcomes of SGA and appropriate size for gestational age (AGA) VLBW infants. We hypothesised that preterm SGA newborns are at increased risk of death, intraventricular haemorrhage (IVH), and periventricular leucomalacia (PVL), but at decreased risk of respiratory distress syndrome (RDS).

\section{METHODS}

\section{Study population}

Data source validation

The Centre for Quality Management in Health Care (CQM) at the Medical Board of Registration in Lower Saxony, Germany prospectively collects perinatal data on almost all children born in the state, and neonatal data on all infants admitted to a hospital within 10 days of birth. Data are recorded using standardised forms or electronically. As this state wide quality assurance programme is especially concerned with VLBW infants, the anonymised, originally separately recorded data of these two databases are linked for this patient group by matching for specific variables. ${ }^{8}$ Thus a total of 380 variables are available from before pregnancy until the child's discharge from hospital. Our analysis was based on all VLBW life births between 1 January 1991 and 31 December $1996(\mathrm{n}=4026)$.

Before data collected for different purposes can be used for research, however, appropriate steps have to be taken to ensure their validity, and inclusion/exclusion criteria established to reduce bias. To examine the external validity of our database and its representativeness for all other German states, we compared our data with those officially recorded at the National Birth Register.'

\section{Exclusion criteria}

Growth status ( SGA, birth weight $<10$ th centile; AGA, 10th to 90th centile; large for gestational age (LGA), >90th centile) was defined according to population based centiles, separately for boys/girls and for singletons/twins. ${ }^{10}$ Twin centiles were used for all multiple births.

Infants were excluded if they:

(a) were too immature to be categorised because of lack of gestational age (GA) specific data $(<23$ weeks for singletons, $<22$ weeks for multiple births)

(b) were LGA

(c) belonged to a GA group not fulfilling the expected distribution of $10 \%$ SGA and $80 \%$ AGA infants, a bias causing sequelae within birthweight cohorts

(d) had severe congenital malformations.

Abbreviations: AGA, appropriate size for gestational age; GA, gestational age; IVH, intraventricular haemorrhage; LGA, large for gestational age; NICU, neonatal intensive care unit; PVL, periventricular leucomalacia; RDS, respiratory distress syndrome; $S G A$, small for gestational age; VLBW, very low birthweight 
Table 1 Comparison of numbers of very low birthweight (VLBW) births in Lower Saxony according to the Centre for Quality Management and the National Birth Register

\begin{tabular}{|c|c|c|c|}
\hline \multirow[b]{2}{*}{$\begin{array}{l}\text { Year of } \\
\text { birth }\end{array}$} & \multicolumn{2}{|c|}{ VLBW births in Lower Saxony } & \multirow[b]{2}{*}{ Captured (\%) } \\
\hline & $\begin{array}{l}\text { Centre for Quality } \\
\text { Management }\end{array}$ & $\begin{array}{l}\text { National Birth } \\
\text { Register }\end{array}$ & \\
\hline 1991 & 603 & 793 & 76.0 \\
\hline 1992 & 637 & 776 & 82.1 \\
\hline 1993 & 629 & 738 & 85.2 \\
\hline 1994 & 680 & 778 & 87.2 \\
\hline 1995 & 745 & 843 & 88.4 \\
\hline 1996 & 832 & 929 & 90.6 \\
\hline Total & 4126 & 4857 & 85.0 \\
\hline
\end{tabular}

Only one sibling of each set of multiples was selected at random, because regression analysis requires non-correlated (independent, disjunctive) individuals.

\section{Variables}

Gestational age was determined by early ultrasound or the last menstrual period, and recorded as completed weeks. RDS was defined as documentation of either this term or of exogenous surfactant administration. Cranial ultrasound was routinely obtained on day $1,3,7$, and 14, with additional investigations in infants with abnormal results. Severe IVH (grade 3/4) was defined as described by Papile et al, ${ }^{11}$ and PVL as described by de Vries et al. ${ }^{12}$ Except for GA and year of birth, all variables were dichotomised using a biologically relevant threshold or the median. The cut off for hospital volume categories-that is, $<36 v \geqslant 36$ VLBW admissions a year-was the one routinely used by the CQM. Five hospitals with $\geqslant 36$ VLBW admissions a year accounted for about $60 \%$ of all admissions; the remainder were from 27 smaller units.

Sex, GA, multiple birth, and, for RDS analyses, application of antenatal corticosteroids were the variables forced into all multivariable models. Moreover, we selected as potential confounders those variables available in the database that were either known confounders based on previous research or suspected to be confounders based on clinical experience. About 40 particular variables for each outcome variable were defined according to the published descriptions of the CQM ${ }^{13}$ and used in univariable analyses.

\section{Study design}

We analysed our data in the form of multiple case-control studies nested within a well defined cohort. SGA infants were the subjects at risk or the "exposed" ones, and AGA infants were the comparison group.

\section{Statistical analysis}

Data source validity

To check external validity and representativeness of the number/percentage of VLBW births in our database among all births nationwide, we calculated the expected number of VLBW births using National Birth Register data, excluding data from Lower Saxony. Traditional standardisation formulas $^{14}$ and continuity corrected $\chi^{2}$ methods ${ }^{15}$ were used. Trend analyses in calendar time were performed by the Cochran-Armitage test. ${ }^{16}$

\section{Mortality analyses}

For univariable survival analysis, graphs of Kaplan-Meier estimators were created. ${ }^{17}$ We then compared survival of SGA and AGA newborns using the log rank test.

Potentially relevant confounders within survival analyses were selected by the log rank test, using an initial $\alpha$ level of 0.25 . Variables with $\alpha<0.25$, plus GA, sex, and multiple birth, were the basis for multivariable, stepwise Cox proportional hazard models. Hazards describe the instantaneous risk of dying. ${ }^{17}$ Stepwise analyses were based on the significant findings according to the Wald $\chi^{2}$ test in the Cox proportional hazard models, reducing the threshold of significance level from $\alpha=0.15$ to $\alpha=0.05$. After having specified a final model, we calculated hazard ratios and corresponding 95\% confidence intervals (CIs). The ratio of two hazards can be interpreted as the relative risk. The specified model was finally checked by plotting the cumulative observed versus the cumulative expected number of deaths as described by Arjas $^{17}$ and by a retrospective power calculation, ${ }^{18}$ expressing the model's ability to show an association between the risk variables and the outcome, if one exists (type II error).

\section{Morbidity analyses}

Univariable analyses based on likelihood ratio tests were performed to detect potential confounders. ${ }^{19}$ The model building strategy for morbidity analyses corresponded to that for survival described above. Based on the final logistic regression model, adjusted odds ratios (adjOR) and 95\% CI

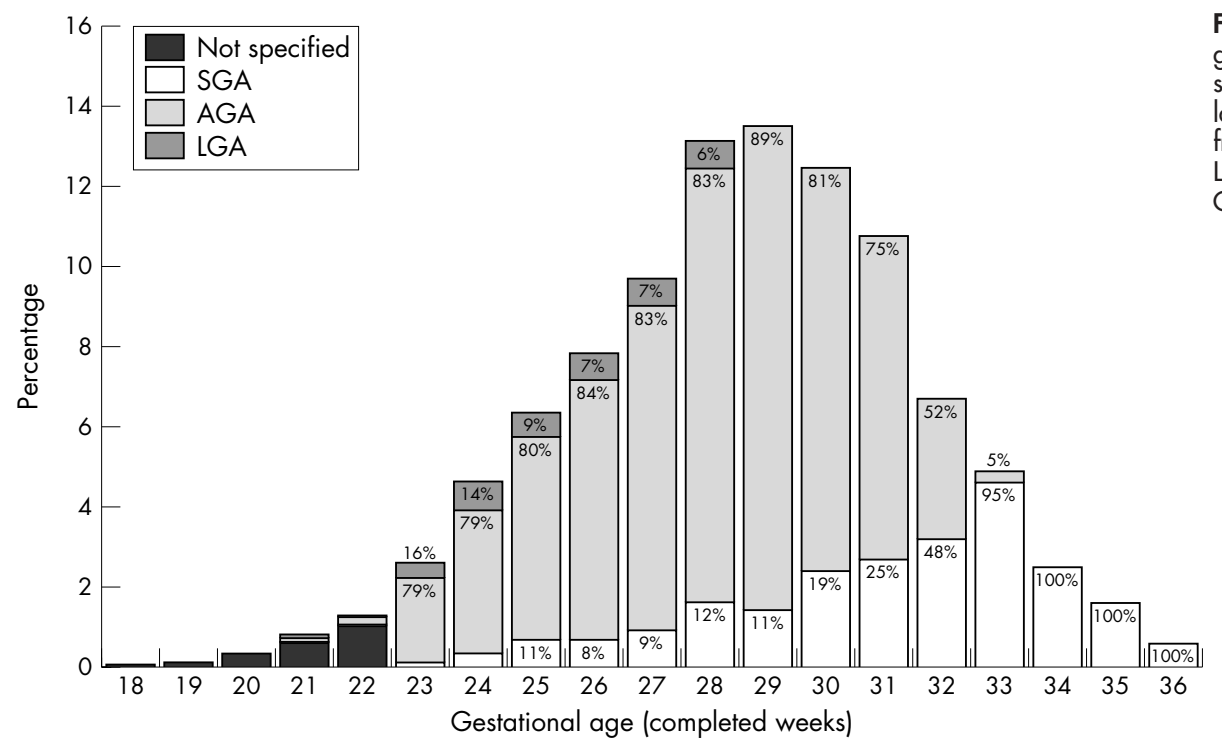

Figure 1 Proportions of small for gestational age (SGA), appropriate size for gestational age (AGA), and large for gestational age (LGA) infants from very low birthweight births in Lower Saxony, 1991-96 (Centre for Quality Management). 


\begin{tabular}{|c|c|c|c|}
\hline & $\begin{array}{l}\text { SGA } \\
(n=173)\end{array}$ & $\begin{array}{l}\text { AGA } \\
(n=1450)\end{array}$ & Total $(n=1623)$ \\
\hline \multicolumn{4}{|c|}{ Maternal characteristics } \\
\hline \multicolumn{4}{|l|}{ Nationality } \\
\hline German & 85.6 & 82.3 & 82.6 \\
\hline Other & 12.7 & 16.7 & 16.3 \\
\hline $\mathrm{MV}$ & 1.7 & 1.0 & 1.1 \\
\hline \multicolumn{4}{|l|}{ Age (years) } \\
\hline$<20$ & 1.2 & 3.6 & 3.3 \\
\hline $20-25$ & 27.2 & 24.3 & 24.7 \\
\hline$>25-30$ & 37.6 & 35.9 & 36.0 \\
\hline$>30-35$ & 24.9 & 24.9 & 24.9 \\
\hline$>35$ & 9.3 & 11.3 & 11.1 \\
\hline \multicolumn{4}{|c|}{ Body mass index } \\
\hline$<20$ & 14.5 & 13.9 & 13.9 \\
\hline $20-24$ & 34.7 & 42.7 & 41.8 \\
\hline $25-29$ & 25.4 & 28.1 & 27.9 \\
\hline $30-39$ & 20.2 & 9.6 & 10.7 \\
\hline$\geqslant 40$ & 2.3 & 0.4 & 0.6 \\
\hline$M V$ & 2.9 & 5.3 & 5.1 \\
\hline \multicolumn{4}{|l|}{ Primiparity } \\
\hline Yes & 55.5 & 37.5 & 39.4 \\
\hline No & 44.5 & 62.4 & 60.5 \\
\hline MV & & 0.1 & 0.1 \\
\hline \multicolumn{4}{|l|}{ Diabetes } \\
\hline No/MV & 98.3 & 99.3 & 99.2 \\
\hline Yes & 1.7 & 0.6 & 0.7 \\
\hline \multicolumn{4}{|c|}{ Neonatal characteristics } \\
\hline \multicolumn{4}{|l|}{ Sex } \\
\hline Male & 46.8 & 53.5 & 52.8 \\
\hline Female & 53.2 & 46.5 & 47.2 \\
\hline \multicolumn{4}{|c|}{ Multiple births } \\
\hline No & 89.6 & 83.1 & 83.8 \\
\hline Yes & 10.4 & 16.9 & 16.2 \\
\hline \multicolumn{4}{|c|}{ Gestational age (weeks) } \\
\hline 25 & 12.7 & 11.9 & 12.0 \\
\hline 26 & 12.1 & 15.9 & 15.5 \\
\hline 27 & 20.2 & 18.8 & 18.9 \\
\hline 28 & 28.9 & 25.1 & 25.5 \\
\hline 29 & 26.0 & 28.3 & 28.0 \\
\hline
\end{tabular}

were calculated. Models were validated by: summary measures of goodness of fit-for example, deviance statistics; predictive power (Somer's D, Gamma, c-statistics), describing how well the outcome variable can be predicted from the influencing variables; and by residual analyses. ${ }^{20}$ All analyses were performed using SAS 8.0/8.2 (SAS Institute, Cary, North Carolina, USA).

\section{RESULTS}

\section{Data source validity}

Comparison of the CQM database with data from the National Birth Register revealed that, from 1991 to 1996, CQM data captured an increasingly large proportion of all births recorded in the national register (table 1). The proportion of VLBW births increased from $0.95 \%$ in 1991 to $1.11 \%$ in $1996(+17 \%)$ in Lower Saxony and from $0.80 \%$ to $0.99 \%$ $(+24 \%)$ in the remaining states. On average, the percentage of VLBW infants was $8.8 \%$ higher in Lower Saxony than in the other German states $(\mathrm{p}<0.05)$. Moreover, the proportion of SGA infants in the Lower Saxonian VLBW cohort increased from $22.7 \%$ in 1991 to $27.4 \%$ in $1996(\mathrm{p}<0.05)$.

\section{Application of exclusion criteria}

In 100 infants $(2.4 \%)$, GA could not be determined because of raw data inconsistencies between the perinatal and neonatal databases, or missing values in either database. In 82 infants $(2.0 \%)$, SGA/AGA/LGA status could not be determined because of lack of published GA specific birthweight centiles.

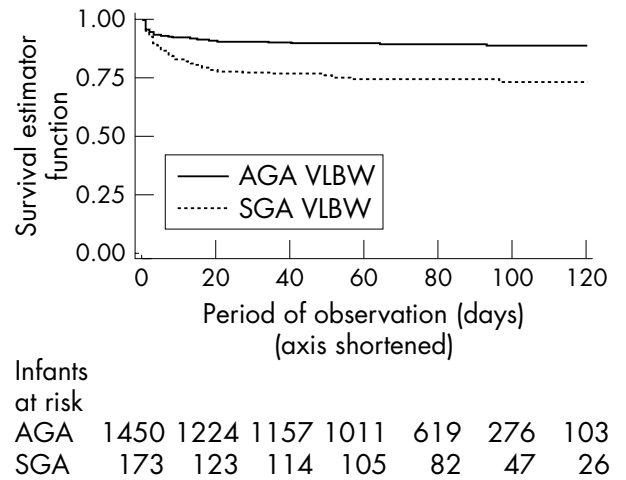

Figure 2 Kaplan-Meier survival estimators (time axis cut). AGA, Appropriate size for gestational age; SGA, small for gestational age; VLBW, very low birthweight.

We further excluded 154 LGA newborns (3.8\%) and 259 $(6.4 \%)$ infants with severe malformations (10.6\% of SGA and $5.1 \%$ of AGA infants). We did not exclude infants from diabetic mothers from the study population, because they comprised only $0.7 \%$ after exclusion of LGA infants.

The expected proportions of both AGA (80\%) and SGA $(10 \%)$ infants were found only among newborns of 2528 weeks gestation (fig 1). At 29 weeks GA, 7\% of AGA infants weighed $>1500 \mathrm{~g}$ and were excluded. This was not associated with an appreciable increase in the proportion of SGA infants (11\%). Thus, GA limits of 25 and 29 weeks were used, resulting in the exclusion of $49.6 \%$ of infants from the original sample $(\mathrm{n}=1996)$.

After having applied all other above mentioned exclusion criteria, random selection of only one sibling from all multiple births was performed. Thus, 1623 independent (disjunctive) VLBW infants with GA of 25-29 weeks and without severe malformations were included in the final study population (table 2). For 28 infants (five SGA), only perinatal information was available because of death in the delivery room. These infants were included for mortality analyses, but were excluded from morbidity analyses.

\section{Mortality}

Overall mortality was $12.1 \%(\mathrm{n}=196), 25.4 \%(\mathrm{n}=44)$ in SGA and $10.5 \%(\mathrm{n}=152)$ in AGA infants. The most common cause of death in both groups was respiratory diseases (overall 33.2\% $(\mathrm{n}=65)$; SGA, 29.6\% $(\mathrm{n}=13)$, AGA, $34.2 \%(\mathrm{n}=52)$. Kaplan-Meier survival estimators

Table 3 Results of multivariable Cox proportional hazard analyses predicting mortality

\begin{tabular}{lll}
\hline Variable & adjHR & $95 \% \mathrm{Cl}$ \\
\hline SGA & $2.54^{*}$ & 1.70 to 3.79 \\
25 weeks & $3.56^{*}$ & 2.06 to 6.13 \\
26 weeks & $2.31^{*}$ & 1.33 to 4.03 \\
27 weeks & 1.73 & 0.99 to 2.99 \\
28 weeks & 0.99 & 0.55 to 1.78 \\
29 weeks & ref. & \\
Male & 1.25 & 0.90 to 1.73 \\
Multiple birth & 1.30 & 0.83 to 2.02 \\
$<36$ VLBW admissions/year & $1.56^{*}$ & 1.12 to 2.18 \\
5 min Apgar $<7$ & $2.01^{*}$ & 1.43 to 2.82 \\
Hypothermia $\left(<35.5^{\circ} \mathrm{C}\right)$ & $1.87^{*}$ & 1.30 to 2.69 \\
IVH 3/4 & $2.67^{*}$ & 1.82 to 3.92 \\
\hline
\end{tabular}

adjHR indicates hazard ratio adjusted for all variables in this table. ${ }^{*} \mathrm{p}<0.05$.

$\mathrm{IVH}$, Intraventricular haemorrhage; SGA, small for gestational age; VLBW, very low birthweight. 
(fig 2) revealed a greater likelihood of survival for AGA infants throughout the entire observation period, which was significant $(\mathrm{p}<0.001)$. Stepwise Cox proportional regression analyses yielded an adjusted hazard ratio of 2.54 (95\% CI 1.70 to 3.79) for SGA compared with AGA infants (table 3). Moreover, in this final regression model decreasing GA, admission to a hospital with less than 36 VLBW admissions a year, a five minute Apgar score $<7$, hypothermia $<35.5^{\circ} \mathrm{C}$ on admission, and IVH grade $3 / 4$ were associated with an increased mortality risk above and beyond the one associated with SGA.

The Arjas plot and retrospectively calculated power of 99.93\% validated the specified model.

\section{Morbidity}

Data on cranial ultrasound results were available for $98.5 \%$ $(\mathrm{n}=1571)$ of infants admitted to neonatal intensive care units (NICUs). Severe IVH was present in $8.4 \%(n=134)$ of infants, affecting 9.5\% $(\mathrm{n}=16)$ of SGA and $8.3 \%(\mathrm{n}=118)$ of AGA infants (adjOR 0.93; 95\% CI 0.50 to 1.65 ; table 4).

For the entire study population $(\mathrm{n}=1595)$, decreasing GA, male sex, multiple birth, hypothermia $<35.5^{\circ} \mathrm{C}$ at NICU admission, sepsis, PVL, and mechanical ventilation for $>10$ days were associated with severe IVH (table 4 ).

PVL was present in $4.6 \%(\mathrm{n}=74)$ of the study population, $8.1 \%(\mathrm{n}=14)$ for SGA and $4.1 \%(\mathrm{n}=60)$ for AGA infants (adjOR $1.54 ; 95 \%$ CI 0.78 to 2.87 ).

Severe IVH and requirement for a surgical procedure during the initial hospital stay were associated with an increased risk of PVL, while tocolysis seemed to be protective (table 5).

According to our definition, $80.3 \%(n=1280)$ of the study sample had RDS. Although this proportion was similar in both groups (80.4\% SGA $v 80.2 \%$ AGA), stepwise logistic regression analysis revealed a significantly reduced RDS risk for SGA infants (adjOR 0.57; 95\% CI 0.35 to 0.93; table 6).

Low GA, male sex, multiple birth, a five minute Apgar score $<7$, hypothermia $<35.5^{\circ} \mathrm{C}$ on admission, sepsis, persistent ductus arteriosus, caesarean section, and admission to a hospital that has more than 35 VLBW admissions a year were significantly associated with an increased occurrence of RDS. In contrast, tocolysis, antenatal steroids, and premature rupture of membranes/chorioamnionitis appeared to be protective. Validation procedures showed good fit of logistic regression models for all of the above morbidity variables (data not shown).

Table 4 Results of multivariable logistic regression analyses predicting intraventricular haemorrhage $3 / 4$

\begin{tabular}{lll}
\hline Variable & adjOR & $95 \% \mathrm{Cl}$ \\
\hline SGA & 0.93 & 0.50 to 1.65 \\
25 weeks & $3.78^{*}$ & 1.91 to 7.74 \\
26 weeks & $2.60^{*}$ & 1.33 to 5.25 \\
27 weeks & $2.84^{*}$ & 1.51 to 5.58 \\
28 weeks & 1.90 & 1.00 to 3.73 \\
29 weeks & Ref & \\
Male & $1.52^{*}$ & 1.04 to 2.23 \\
Multiple birth & $1.74^{*}$ & 1.09 to 2.71 \\
Hypothermia $\left(<35.5^{\circ} \mathrm{C}\right)$ & $1.95^{*}$ & 1.27 to 2.97 \\
Sepsis & $1.49^{*}$ & 1.02 to 2.16 \\
PVL & $4.19^{*}$ & 2.31 to 7.39 \\
Mechanical ventilation & $1.60^{*}$ & 1.08 to 2.40 \\
( $\geqslant 10$ days) & & \\
\hline
\end{tabular}

adjOR indicates odds ratio adjusted for all variables in this table. ${ }^{*} \mathrm{p}<0.05$.

PVL, Periventricular leucomalacia; SGA, small for gestational age.
Table 5 Results of multivariable logistic regression analyses predicting periventricular leucomalacia

\begin{tabular}{lll}
\hline Variable & adjOR & $95 \% \mathrm{Cl}$ \\
\hline SGA & 1.54 & 0.78 to 2.87 \\
25 weeks & 0.97 & 0.34 to 2.55 \\
26 weeks & 2.10 & 0.96 to 4.70 \\
27 weeks & 1.01 & 0.42 to 2.39 \\
28 weeks & $2.08^{*}$ & 1.03 to 4.39 \\
29 weeks & Ref & \\
Male & 0.78 & 0.47 to 1.23 \\
Multiple birth & 0.78 & 0.35 to 1.56 \\
IVH 3/4 & $4.91^{*}$ & 2.69 to 8.72 \\
Surgery & $1.91^{*}$ & 1.12 to 3.22 \\
Tocolysis & $0.48^{*}$ & 0.28 to 0.81 \\
\hline
\end{tabular}

adjOR indicates odds ratio adjusted for all variables in this table. ${ }^{*} \mathrm{p}<0.05$.

IVH, Intraventricular haemorrhage; SGA, small for gestational age.

\section{DISCUSSION}

Data from a quality control programme can be used for epidemiological analyses, provided that data clean up is performed using a priori criteria. We found more than 2.5fold increased mortality in SGA compared with AGA VLBW infants, but no difference in severe IVH or PVL. RDS was less common in SGA infants. For both groups, the risk of death before hospital discharge was more than 50\% higher in infants admitted to small NICUs.

\section{Data source validity}

A major strength is the use of population based data. Whereas single centre analyses ${ }^{21-23}$ are less representative and prone to selection bias, our database provided large enough numbers for most multivariable analyses and detection of potential differences. ${ }^{22}{ }^{24}$ Also, the data validation process in this study is unique. To our knowledge, comparison of data from two sources-that is, the CQM and the National Birth Register-to maximise data validity has not been performed before in VLBW studies. However, when data from different sources are compared, potentially

Table 6 Results of multivariable logistic regression analyses predicting respiratory distress syndrome

\begin{tabular}{|c|c|c|}
\hline Variable & AdjOR & $95 \% \mathrm{Cl}$ \\
\hline SGA & $0.57^{*}$ & 0.35 to 0.93 \\
\hline 25 weeks & $6.67^{*}$ & 3.31 to 15.03 \\
\hline 26 weeks & $1.85^{\star}$ & 1.17 to 2.96 \\
\hline 27 weeks & $2.05^{*}$ & 1.36 to 3.15 \\
\hline 28 weeks & 1.38 & 0.98 to 1.95 \\
\hline 29 weeks & ref. & \\
\hline Male & $1.51^{*}$ & 1.14 to 2.00 \\
\hline Multiple birth & $2.17^{*}$ & 1.42 to 3.44 \\
\hline 1991 (year of birth) & Ref & \\
\hline 1992 & $1.85^{*}$ & 1.04 to 3.31 \\
\hline 1993 & 1.05 & 0.61 to 1.81 \\
\hline 1994 & 0.64 & 0.38 to 1.06 \\
\hline 1995 & 0.63 & 0.38 to 1.05 \\
\hline 1996 & 0.64 & 0.39 to 1.06 \\
\hline$<36$ VLBW admissions/year & $0.58^{*}$ & 0.43 to 0.77 \\
\hline 5 min Apgar $<7$ & $1.83^{*}$ & 1.23 to 2.78 \\
\hline Hypothermia $\left(<35.5^{\circ} \mathrm{C}\right)$ & $1.67^{*}$ & 1.07 to 2.69 \\
\hline Sepsis & $2.05^{\star}$ & 1.52 to 2.79 \\
\hline PDA & $3.15^{*}$ & 2.11 to 4.82 \\
\hline PROM/chorioamnionitis & $0.61 *$ & 0.45 to 0.83 \\
\hline Tocolysis & $0.59^{*}$ & 0.43 to 0.82 \\
\hline Antenatal steroids & $0.60^{*}$ & 0.42 to 0.84 \\
\hline Caesarean section & $2.07^{*}$ & 1.39 to 3.01 \\
\hline
\end{tabular}


different data management strategies have to be considered. Within birth registers, missing values are often completed by substitution techniques, whereas the CQM performs extensive research on them.

The considerable discrepancies from birth registry data were in part attributable to data from four small hospitals, with a cumulative birth number of 1700/year, not participating in the quality assurance programme, and to failures of perinatal and neonatal data set linkages, which declined from $8 \%$ to $0 \%$ from 1991 to 1996 . Differences in eligibility criteria between the CQM and National Birth Register appeared to be the main reason for these discrepancies. Whereas the National Birth Register counts neonates from mothers resident in Lower Saxony independent of place of birth, the CQM counts only those born in the state. Two of Lower Saxony's neighbours, the city states Hamburg and Bremen, have large perinatal centres, and a migration effect was indeed found by the CQM to explain the differences observed (Paul Wenzlaff, personal communication). However, as deficits in captured data were not equally distributed over time, we defined birth year as a potential confounder in the subsequent outcome analysis.

There was a significant rise within the six year observation period in the proportion of all VLBW infants and those who were SGA. An increase in the proportion of VLBW infants over time has also been reported from other regions. ${ }^{25-27}$ This has been attributed to an increase in the average age of primiparous women, ${ }^{28}$ the number of assisted conceptions, ${ }^{29}$ and the number of immigrants from foreign countries, who are more prone to multiple births. ${ }^{30-32}$ It may also be related to an increased use of ultrasound examinations, resulting in more precise GA determinations and earlier obstetrical interventions. ${ }^{25} 2633$ Unfortunately, adequate data for corresponding analyses were not available. However, in our database, we could at least detect an increase in maternal age and in the proportion of multiple births among all VLBW births.

Data on changes in the proportion of SGA infants are conflicting. ${ }^{34}$ While average birth weight and the proportion of LGA infants appear to increase over time, ${ }^{35}$ one group also reported an increase in the proportion of SGA infants within a cohort of very preterm twins. ${ }^{36}$ Possible explanations for this increase include those mentioned above, particularly the increased use of prenatal ultrasound. ${ }^{37}$

\section{Exclusion criteria}

We refrained from defining our study population by birth weight to avoid unequal proportions of SGA newborns across different GA groups. ${ }^{48}$ Implementing GA limits also yields representative male/female ratios. This avoids an overestimation of risks associated with male sex, caused by male newborns, who have higher body mass, ${ }^{39}$ being gestationally younger than their female birthweight peers. Bias may also result from comparing SGA newborns with non-SGA infants, the latter including both AGA and LGA newborns in the control group. ${ }^{40}$ In addition, we did not exclude all multiple births, ${ }^{4041}$ but randomly selected only one sibling, which allowed us to consider multiple births as a potential confounder.

\section{What is already known on this topic}

(a) SGA infants are at increased mortality risk

(b) Results on morbidity are conflicting

(c) Multivariable analysis of large cohorts are necessary, but difficult
Finally, statistical analysis is a crucial factor in comparing SGA and AGA infants, and represents a major cause for conflicting results. Often only univariable analyses are applied, ${ }^{42}$ adjustment for essential confounders (such as $\mathrm{GA}^{23}$ ) is missing, or no model validations are performed.

\section{Mortality}

Cox proportional hazard models allowed quantification of the increased mortality of SGA VLBW infants with respect to postnatal age and many confounders. The increased mortality was not related to length of NICU stay. Indeed, most deaths in both groups occurred in the first four weeks of life (fig 2). Some authors, albeit not using the Cox proportional hazard model, have also found such a risk increase, ${ }^{414} 44$ whereas others have reported the opposite effect, probably caused by GA differences between groups or lack of multivariable analysis. $^{2145}$

\section{Morbidity}

Our findings and those of others ${ }^{22}$ do not support the hypothesis that SGA infants are at increased risk of severe IVH. The main reason for discrepancies from other studies may be related to ignoring $\mathrm{GA}^{24}$ the exclusive use of univariable analyses, ${ }^{46}$ or lack of distinguishing different effects - that is, SGA may per se be protective against IVH, or maternal hypertension/pre-eclampsia, a known risk factor for growth restriction, may be protective. ${ }^{47}$

Being SGA was also not associated with an increased risk of PVL. This result has to be viewed with caution. Firstly, the number of cases was small. Secondly, information bias resulting from the use of different ultrasound scanners $(5 \mathrm{v}$ 7.5 MHz) cannot be ruled out. Thirdly, PVL may be more prevalent in infants of $>28$ weeks gestation. ${ }^{48}$ Our study population was limited to infants of $\leqslant 29$ weeks gestation, perhaps excluding infants at greatest risk of PVL.

It has previously been reported by some, ${ }^{22}{ }^{49}$ but not others, ${ }^{43}$ that SGA is associated with a reduced risk of RDS. Insufficient control for confounders is a likely source of these inconsistencies.

The definition for RDS used in this study, although inherently somewhat imprecise, reflects current neonatal practice in Germany, where the decision to intubate is based on signs of respiratory distress and oxygen requirement in

\section{What this study adds}

(a) Use of data collected for other reasons than the question under study requires a detailed data validation process, definition of inclusion/exclusion criteria, and analysis based on multivariable models, controlling for potential prenatal, perinatal, and postnatal confounders

(b) The proportion of both VLBW and SGA infants increased significantly during the period of observation (1991-96)

(c) SGA VLBW infants have more than twice the mortality risk as their AGA peers, but no increased risk of severe intraventricular haemorrhage or periventricular leucomalacia; they are even at decreased risk of developing respiratory distress syndrome

(d) VLBW infants admitted to smaller units $1<36$ VLBW admissions a year) have a $60 \%$ higher mortality than those admitted to larger units, despite indicators suggesting a higher disease severity in the latter group 
the delivery room, with surfactant being given immediately after intubation. This practice precludes a diagnosis of RDS based only on chest radiographs.

Gestational age affected all outcome variables, except for PVL; reasons for the latter are discussed above. Boys and multiple births were at greater risk of IVH and RDS. As there are no other studies with independent (disjunctive) individuals from multiple births, these results deserve further investigation. The predictive value of the Apgar score is well established and evident in mortality and RDS analyses. However, the Apgar score as a variable represents a melange of multiple confounders, in part directly related to the outcome variable-for example, RDS - and in part related to unmeasured exposures. Hypothermia $\left(<35.5^{\circ} \mathrm{C}\right)$ was associated with death, severe IVH, and RDS, as shown by others. $^{2150}$ Hypothermia may be both a cause and an outcome, the latter being the consequence of a prolonged and/or difficult resuscitation resulting from RDS or IVH. Similarly, the apparent influence of tocolysis, seemingly protective against PVL and RDS, ${ }^{51}{ }^{52}$ has to be interpreted with caution because the reason for this protective effect may simply lie in a prolongation of pregnancy.

We found a link between severe IVH and PVL. This is not yet fully understood..$^{53}$ PVL is more common in infants undergoing surgery, ${ }^{55}$ possibly because of blood pressure fluctuations occurring during the procedure and/or inflammatory mediators resulting from surgery. Moreover, PVL and the disorder treated by surgery may share aetiological characteristics. The association between IVH 3/4 and mortality may be real, but reporting bias may also have contributed to this finding, because in cases of poor prognosis and reduced medical treatment, severe IVH is often recorded as cause of death. ${ }^{56}$

Our study has an important public health aspect. Mortality was $56 \%$ higher in infants admitted to hospitals with fewer than 36 VLBW admissions a year, despite the admission of sicker newborns to larger hospitals (>35 VLBW infants/year; see data on RDS) and their larger proportion of outborn infants. This observation provides further evidence for the importance of centralising perinatal care. ${ }^{57}$

It would have been interesting also to analyse data on bronchopulmonary dysplasia and retinopathy of prematurity. Unfortunately, changes in definition and/or documentation during the observation period rendered this impossible. Also, preterm birth may in itself create a bias towards SGA because of a higher risk of extremely preterm birth in severely growth retarded fetuses. ${ }^{23}$ Appropriate fetal growth charts, however, were not available for the population under study.

\section{CONCLUSIONS}

Population based data collected for purposes other than epidemiological research can indeed be used for epidemiological analyses, provided that an a priori clearly established data clean up procedure is applied. Our analyses reveal a significantly increased mortality of SGA VLBW infants (GA 25-29 weeks) compared with their AGA peers, without noticeable increases in severe IVH or PVL, and a reduced risk of RDS. This calls for further studies into the underlying reasons for this observation. The prognostic relevance of antenatal transport of high risk newborns to tertiary care centres emphasises the need to enforce perinatal regionalisation.

Population based, valid, multivariable studies are necessary to obtain valid data on the potential risks for SGA newborns. Understanding the complexity of intrauterine growth restriction, and its consequences, will help to identify infants at greatest risk, and, eventually, will help prevent adverse pregnancy outcome.

\section{ACKNOWLEDGEMENTS}

We are grateful to Martin Schlaud, MD, for his helpful comments on the data analysis.

\section{Authors' affiliations}

D B Bartels, O Dammann, Perinatal Epidemiology Infectious Diseases Unit, Departments of Pediatrics and Obstetrics, Hannover Medical

School, Hannover, Germany

L Kreienbrock, Department of Biometry, Epidemiology and Information Processing, WHO Centre for Research and Training in Veterinary Public Health, School of Veterinary Medicine Hannover, Hannover

O Dammann, Neuroepidemiology Unit, Department of Neurology, Children's Hospital and Harvard Medical School of Public Health, Boston, Massachusetts 02115, USA

P Wenzlaff, Centre for Quality Management in Health Care, Hannover C F Poets, Department of Neonatology, University of Tübingen, Tübingen, Germany

Competing interests: none declared

\section{REFERENCES}

1 Kramer MS. Determinants of low birth weight: methodological assessment and meta-analysis. Bull WHO 1987;65:663-737

2 Mclntire DD, Bloom SL, Casey BM, et al. Birth weight in relation to morbidity and mortality among newborn infants. N Engl J Med 1999;340:1234-8.

3 Meyberg R, Boos R, Babajan A, et al. [Intrauterine growth retardation: perinatal mortality and postnatal morbidity in a perinatal center.] $Z$ Geburtshilfe Neonatol 2000;204:218-23.

4 Arnold CC, Kramer MS, Hobbs CA, et al. Very low birth weight: a problematic cohort for epidemiologic studies of very small or immature neonates. Am J Epidemiol 1991;134:604-13.

5 Moore ML, Michielutte R, Meis PJ, et al. Etiology of low-birthweight birth: a population-based study. Prev Med 1994;23:793-9.

6 Clausson B, Cnattingius S, Axelsson O. Preterm and term births of small for gestational age infants: a population-based study of risk factors among nulliparous women. Br J Obstet Gynaecol 1998;105:1011-17.

7 Meirowitz NB, Ananth CV, Smulian JC, et al. Effect of labor on infant morbidity and mortality with preterm premature rupture of membranes: United States population-based study. Obstet Gynecol 2001;97:494-8.

8 Bartels D, Kreienbrock L, Wenzlaff $P$, et al. Can data from a neonatal quality control program be used for epidemiologic studies? Pediatr Res 2002;52:781.

9 Statistisches Bundesamt W. In: Statistisches Bundesamt, 65180 Wiesbaden.

10 Voigt M, Schneider KT, Jahrig K. [Analysis of a 1992 birth sample in Germany. 1: New percentile values of the body weight of newborn infants.] Geburtshilfe Fravenheilkd 1996;56:550-8.

11 Papile LA, Burstein J, Burstein R, et al. Incidence and evolution of subependymal and intraventricular hemorrhage: a study of infants with birth weights less than 1,500 gm. J Pediatr 1978;92:529-34.

12 de Vries LS, Eken P, Dubowitz LM. The spectrum of leukomalacia using cranial ultrasound. Behav Brain Res 1992;49:1-6.

13 Perinatologische Arbeitsgemeinschaft N. Kurzanleitung zum Ausfüllen des neonataologischen Erhebungsbogens. Hannover: PAG, 1989.

14 Rothmann K, Greenland S. Modern epidemiology, 2nd ed. Philadelphia: Lippincott Williams \& Wilkins, 1998.

15 Breslow N, Day NE. Statistical methods in cancer research. Volume II The design and analysis of cohort studies. New York: Oxford University Press, 1987.

16 Agresti A. Categorical data analysis. New York: John Wiley \& Sons, Inc, 1990.

17 Hosmer D, Lemeshow S. Applied survival analysis: regression modeling of time to event data. New York: John Wiley \& Sons, 1999.

18 Bock J. Bestimmung des Stichprobenumfangs, 2nd ed. München: R Oldenbourg Verlag, 1998.

19 Hosmer D, Lemeshow S. Applied logistic regression. New York: John Wiley \& Sons, 1989.

20 Allison P. Logistic-regression using the SAS system: theory and application. North Carolina: SAS Institute, 1999.

21 Harms K, Osmers R, Kron M, et al. [Mortality of premature infants 19801990: analysis of data from the Gottingen perinatal centre.] Z Geburtshilfe Perinatol 1994; 198:126-33.

22 Simchen MJ, Beiner ME, Strauss-Liviathan N, et al. Neonatal outcome in growth-restricted versus appropriately grown preterm infants. Am J Perinatol 2000;17:187-92.

23 Zaw W, Gagnon R, da Silva O. The risks of adverse neonatal outcome among preterm small for gestational age infants according to neonatal versus fetal growth standards. Pediatrics 2003;111:1273-7.

24 Jensen A. [The risk of cerebral hemorrhage in the newborn infant.] Gynakologe 1992;25:176-86.

25 Joseph KS, Kramer MS, Marcoux S, et al. Determinants of preterm birth rates in Canada from 1981 through 1983 and from 1992 through 1994. N Engl J Med 1998;339:1434-9.

26 Kramer MS, Platt R, Yang H, et al. Secular trends in preterm birth: a hospitalbased cohort study. JAMA 1998;280:1849-54. 
27 Craig ED, Thompson JM, Mitchell EA. Socioeconomic status and preterm birth: New Zealand trends, 1980 to 1999. Arch Dis Child Fetal Neonatal Ed 2002;86:F142-6

28 Hoyert DL, Freedman MA, Strobino DM, et al. Annual summary of vital statistics: 2000. Pediatrics 2001;108:1241-55.

29 Bergh T, Ericson A, Hillensjo T, et al. Deliveries and children born after in-vitro fertilisation in Sweden 1982-95: a retrospective cohort study. Lancet 1999;354:1579-85.

30 Cogswell ME, Yip R. The influence of fetal and maternal factors on the distribution of birthweight. Semin Perinatol 1995; 19:222-40.

31 Oleszczuk JJ, Cervantes A, Kiely JL, et al. Maternal race/ethnicity and twinning rates in the United States, 1989-1991. J Reprod Med 2001;46:550-7.

32 Lang JM, Lieberman E, Cohen A. A comparison of risk factors for preterm labor and term small-for-gestational-age birth. Epidemiology 1996;7:369-76.

33 Goldenberg RL, Davis RO, Cutter GR, et al. Prematurity, postdates, and growth retardation: the influence of use of ultrasonography on reported gestational age. Am J Obstet Gynecol 1989;160:462-70.

34 Ananth CV, Wen SW. Trends in fetal growth among singleton gestations in the United States and Canada, 1985 through 1998. Semin Perinatol 2002;26:260-7.

35 Kramer MS, Morin I, Yang H, et al. Why are babies getting bigger? Temporal trends in fetal growth and its determinants. J Pediatr 2002;141:538-42.

36 Kogan MD, Alexander GR, Kotelchuck M, et al. Trends in twin birth outcomes and prenatal care utilization in the United States, 1981-1997. JAMA 2000;284:335-41.

37 Joseph KS, Kramer MS, Allen AC, et al. Implausible birth weight for gestational age. Am J Epidemiol 2001;153:110-13.

38 Dammann O, Dammann CE, Allred EN, et al. Fetal growth restriction is not associated with a reduced risk for bilateral spastic cerebral palsy in very-low birthweight infants. Early Hum Dev 2001;64:79-89.

39 Stevenson DK, Verter J, Fanaroff AA, et al. Sex differences in outcomes of very low birthweight infants: the newborn male disadvantage. Arch Dis Child Fetal Neonatal Ed 2000;83:F182-5.

40 Regev RH, Lusky A, Dolfin T, et al. Excess mortality and morbidity among small-for-gestational-age premature infants: a population-based study. J Pediatr 2003;143:186-91.

41 Piper JM, Xenakis EM, McFarland M, et al. Do growth-retarded premature infants have different rates of perinatal morbidity and mortality than appropriately grown premature infants? Obstet Gynecol 1996;87:169-74.
42 Gortner L, Waver RR, Stock GJ, et al. Neonatal outcome in small for gestational age infants: do they really better? J Perinat Med 1999:27:484-9.

43 Spinillo A, Capuzzo E, Piazzi G, et al. Significance of low birthweight for gestational age among very preterm infants. Br J Obstet Gynaecol 1997; 104:668-73

44 Bernstein IM, Horbar JD, Badger GJ, et al. Morbidity and mortality among very-low-birth-weight neonates with intrauterine growth restriction. The Vermont Oxford Network. Am J Obstet Gynecol 2000;182:198-206.

45 Bancher-Todesca D, Lee A, Dadak C, et al. [Morbidity and mortality of retarded and normal weight premature infants.] Z Geburtshilfe Neonatol 1995; 199:54-7.

46 Sims ME, Troy C, Walther FJ. Are small for gestational age infants at higher risk for intracranial lesions? Am J Perinatol 1992;9:152-3.

47 Hill A. Intraventricular hemorrhage: emphasis on prevention. Semin Pediatr Neurol 1998:5:152-60.

48 Leviton A, Paneth N. White matter damage in preterm newborns: an epidemiologic perspective. Early Hum Dev 1990;24:1-22.

49 Zupan V, Gonzalez P, Lacaze-Masmonteil T, et al. Periventricular leukomalacia: risk factors revisited. Dev Med Child Neurol 1996;38:1061-7.

50 Costeloe K, Hennessy E, Gibson AT, et al. The EPICure study: outcomes to discharge from hospital for infants born at the threshold of viability. Pediatrics 2000;106:659-71.

51 Volpe JJ. Brain injury in the premature infant. Neuropathology, clinical aspects, pathogenesis, and prevention. Clin Perinatol 1997;24:567-87.

52 FineSmith RB, Roche K, Yellin PB, et al. Effect of magnesium sulfate on the development of cystic periventricular leukomalacia in preterm infants. Am J Perinatol 1997; 14:303-7.

53 Dammann O, Leviton A. Maternal intrauterine infection, cytokines, and brain damage in the preterm newborn. Pediatr Res 1997;42:1-8.

54 Volpe JJ. Neurobiology of periventricular leukomalacia in the premature infant. Pediatr Res 2001;50:553-62.

55 Trounce JQ, Shaw DE, Levene MI, et al. Clinical risk factors and periventricular leucomalacia. Arch Dis Child 1988;63:17-22.

56 Hiersche H, Hirsch G, Graf-Baumann T. Grenzen ärztlicher Behandlungspflicht bei schwerstgeschädigsten Neugeborenen. In: Einbecker Workshop der Deutschen Gesellschaft für Medizinrecht; 1986 1987. Einbeck: Springer Verlag, 1986.

57 Chien LY, Whyte R, Aziz K, et al. Improved outcome of preterm infants when delivered in tertiary care centers. Obstet Gynecol 2001;98:247-52. 